\title{
Estimation of Minimum Miscibility Pressure for Flue Gas Injection Using Soft Experimentations
}

\author{
Oluwaseun Oyinloye ${ }^{1}$, Naeema Al Darmaki ${ }^{2}$, Mohamed Al Zarooni ${ }^{*}$, \\ Fathi Boukadi' ${ }^{1}$ Hildah Nantongo ${ }^{2}$ \\ ${ }^{1}$ Department of Petroleum Engineering, University of Louisiana, Lafayette, Louisiana, USA \\ ${ }^{2}$ Department of Chemical and Petroleum Engineering, UAE University, Al-Ain, United Arab Emirates \\ ${ }^{3}$ Department of Chemical and Petroleum Engineering, American University of Ras Al Khaimah, Ras Al Khaimah, United Arab \\ Emirates \\ Email: seunoyinloye@outlook.com, Naeema.i@uaeu.ac.ae,*mohamed.zarooni@aurak.ac.ae, \\ fboukadi@louisiana.edu,nhildah89@gmail.com
}

How to cite this paper: Oyinloye, O., $\mathrm{Al}$ Darmaki, N., Al Zarooni, M., Boukadi, F. and Nantongo, H. (2021) Estimation of Minimum Miscibility Pressure for Flue Gas Injection Using Soft Experimentations. Natural Resources, 12, 363-381. https://doi.org/10.4236/nr.2021.1211025

Received: September 28, 2021

Accepted: November 27, 2021

Published: November 30, 2021

Copyright $\odot 2021$ by author(s) and Scientific Research Publishing Inc. This work is licensed under the Creative Commons Attribution International License (CC BY 4.0).

http://creativecommons.org/licenses/by/4.0/ (c) (i) Open Access

\begin{abstract}
A new approach is demonstrated in which soft experimentation can be performed for MMP measurements, thus replacing the common practice of slim tube displacement laboratory experiments. Recovery potential from oil reservoirs by miscible flue gas injection was studied by slim tube and field-scale numerical simulation using two flue gases and seven crude oils sampled at different depths in three candidate reservoirs. The soft experimentations were conducted using Eclipse $300^{\mathrm{TM}}$, a three-phase compositional simulator. This study investigates minimum miscibility pressure (MMP), a significant miscible gas injection project screening tool. Successful design of the project is contingent to the accurate determination of the MMP. This study evaluates effects of important factors such as injection pressure, oil component composition, and injection gas composition on the MMP and recovery efficiency for slim tube and field-scale displacements. Two applicable MMP correlations were used for comparison and validation purposes.
\end{abstract}

\section{Keywords}

Empirical Correlation, Minimum Miscibility Pressure, Slim-Tube Soft

Experimentation, Field-Scale Numerical Simulation, Flue Gas Injection

\section{Introduction}

Enhanced oil recovery (EOR) techniques yield incremental oil from light oil reservoirs. [1] indicated that the application of EOR processes depends on reservoir temperature, pressure, depth, net oil pay, permeability, residual oil and wa- 
ter saturations, porosity, oil API gravity, and oil viscosity.

At today's oil prices, the use of flue gas makes the recovery process cost effective and enhances $\mathrm{CO}_{2}$ sequestration efforts. Flue gas has the ability to achieve dynamic miscibility with light oils (API gravity $>35^{\circ}$ ) at high in-situ pressures. According to [2], flue gas composition is typically $85 \%$ to $88 \%$ nitrogen and $15 \%$ to $12 \%$ carbon dioxide. In light oil reservoirs, EOR combines solvent extraction, interfacial tension reduction, and oil viscosity change to produce incremental oil.

In solvent flooding, compositional simulation is a tool that can be used in prediction of recovery. Such simulation is used when an equation of state is required to describe reservoir fluid phase behavior or compositional changes associated with depth. The effects of key parameters such as MMP using crude oil composition, flue gas composition, injection pressure, reservoir temperature, and pressure on the performance recovery in miscible flooding could be estimated using simulators such as ECLIPSE $300^{\mathrm{TM}}$. MMP is the pressure that defines whether the displacement mechanism is miscible or immiscible. It is also defined as the lowest pressure at which the injected gas can develop miscibility with the reservoir oil at reservoir temperature and pressure.

In this work, one potential application of this new soft experimentation approach is shown in the prediction of MMP and investigating the fact that field simulation can replace expensive slim tube experiments in the estimation of an accurate MMP.

\section{Literature Review}

The gas injection technique has been widely used to enhance oil recovery in carbonate and sandstone reservoirs [3]. It was added that incremental oil recovery from $\mathrm{CO}_{2}$ floods, in the U.S., yielded about 15 billion barrels [4]. The authors explained that the vast majority of the $\mathrm{CO}_{2}$ floods were used during tertiary recovery of mature oil reservoirs, which have been water flooded for years. The effect of flue gas displacement on light oil at a reservoir temperature of $240.8^{\circ} \mathrm{F}$ and a pressure range of 4007 to 6680 psi was studied. The experimental results indicated that a combination of vaporizing and condensing multi-contact drive mechanisms led to oil displacement. Studies also showed that flue gases became nearly miscible at high pressures. This is an indication that high-pressure flue gas injection is cost-effective for EOR of light oils, compared to rich gas or water injection. Besides, the added potential of $\mathrm{CO}_{2}$ sequestration makes flue gas injection a more attractive EOR recovery technique.

A substantial amount of work has been carried out by various researchers on flue gas injection with the purpose of enhancing recovery through miscibility or near-miscibility, at elevated pressures. The experiments are generally carried out at a wide range of pressures and oil recovery is plotted against injection pressure. The pressure beyond which oil recovery shows no significant increase is also defined as the MMP. The first estimated MMP [5] needed volume of gas enrich- 
ment for a condensing-drive mechanism which was correlated with temperature, pressure, gas intermediate fractions, and gas heavy fractions of oil samples. The Peng-Robinson equation-of-state was used to develop a correlation for condensing-drive mechanisms [6]. The empirical equation was applicable for a wider range of temperature, pressure, and fluid compositions. It was demonstrated that MMP can be predicted using compositional simulation [7] and noted that numerical dispersion can be a problem and needs to be reduced. A work for displacement of oil with arbitrary number of gas components was extended [8] [9]. In this study, a review of the literature of several MMP correlations of vaporizing and condensing gas drive mechanisms was investigated.

An MMP correlation was developed for vaporizing and condensing gas drives, $\mathrm{CO}_{2}$, and $\mathrm{N}_{2}$ systems [10]. The input parameters were temperature, mole percent of methane in the injection gas, molecular weight of $\mathrm{C}_{2}-\mathrm{C}_{6}$ intermediates, and molecular weight of the heptane plus fraction of oil. A new parameter called, paraffin characterization factor $(\mathrm{k})$, was defined to account for oil composition effect on MMP. In addition, the vaporizing gas drive with the PR-EOS and a compositional simulator was modeled [11]. The authors proposed a simple correlation to estimate the MMP of Nitrogen and lean-gas systems. MMP was correlated as a function of temperature, molar concentration of intermediates, and molecular weights of heavy fractions of oil. Many available MMP correlations in the literature were developed for $\mathrm{CO}_{2}$ or impure $\mathrm{CO}_{2}$ flooding.

It was also stated that MMP is a significant parameter in establishing full-contact miscibility between oil and gas [12]. Using modified conjugate gradient and global optimizing methods, a new $\mathrm{CO}_{2}$-crude oil MMP correlation has been derived. To develop the equation, 210 date sets have been utilized. The new parametric equation used reservoir temperature, $\mathrm{C}_{7}^{+}$molecular weight, and mole fractions of $\mathrm{CH}_{4}, \mathrm{~N}_{2}, \mathrm{CO}_{2}, \mathrm{H}_{2} \mathrm{~S}$, and $\mathrm{C}_{2}-\mathrm{C}_{6}$ as independent parameters. Compared to published MMP correlations, the new model showed better MMP predictions with a percentage average absolute relative error (\%AARE) of $8 \%$ and a percentage maximum absolute relative error (\%MARE) of $21 \%$, respectively.

To estimate MMP, a general regression neural network (GRNN) model was introduced [13]. The model used crude oil composition and temperature as independent variables. The developed model was trained with 91 sample measurements and was validated with 22. Part of the data was from experimental measurements at the Petroleum Fluid Research Centre at Kuwait University. Other data was collected from literature. The training and testing data sets indicated average absolute errors of $0.2 \%$ and $3.3 \%$, respectively.

The effect of pure $\mathrm{N}_{2}$, pure $\mathrm{CO}_{2}$, and flue gas on oil recovery in tight Eagle Ford formations was also investigated [14]. For flue gas, they used a 50:50 $\mathrm{N}_{2}$ to $\mathrm{CO}_{2}$ ratio. Injection pressures were varied from 1000 to 5000 psi with pressure increments of 1000 psi. Flooding times were limited to six hours. Results showed that the use of pure $\mathrm{CO}_{2}$ gave the highest recovery. Flue gas came second and enhanced oil recovery using pure $\mathrm{N}_{2}$ gave the lowest incremental oil. Break- 
through times, however, showed conflicting results. Pure $\mathrm{N}_{2}$ broke through earlier and flue gas breakthrough time was the longest. The authors also indicated that recovery factor $(\mathrm{RF})$ decreased for all three cases, when injection pressure was above 3000 psi.

A new model that better predicts $\mathrm{CO}_{2}$-oil MMP was presented and the authors indicated that their method eliminates the need to locate key tie lines [15]. Unlike traditional correlations, they added that their technique considers the effect of multiple contact. To develop the new model, the authors used reservoir temperature and oil composition. The data utilized in model generation used five Chinese crude oil samples. These samples came from different oilfields. The injected gas was pure $\mathrm{CO}_{2}$. The authors showed that predicted MMP came within $2 \%$ of the measured MMPs.

MMP correlations that will be used for comparative purposes are applicable for nitrogen $/ \mathrm{CO}_{2}$ flooding [10] [11]. Reliability of each individual correlation will be evaluated by determining, how close the predictive minimum miscibility pressures are to the numerical simulation results.

\section{Method}

\subsection{Compositional Simulation of Flue Gas Injection Processes}

EOS based fluid property simulation packages are usually used to describe the reservoir oils for compositional flow simulation purposes. The effect of oil and flue gas compositions on oil recovery, in the flue-gas/light oil injection processes, has been studied using a fluid property-based simulation package to tune the PR-EOS to a 10-component fluid system [1]. The PR-EOS was used with volume correction to improve the prediction of phase densities. Inputs of the simulator are reservoir temperature and composition of the recombined oil. Physical properties of $\mathrm{C}_{1}$ to $\mathrm{C}_{6}$ hydrocarbon components as well as the non-hydrocarbon components were also entered from the pure component library properties. Properties of the heavy hydrocarbon fractions $\left(\mathrm{C}_{7}\right.$ to $\left.\mathrm{C}_{66}\right)$ were obtained from their molecular mass and boiling point of the fractions. Specific gravity, critical properties, and acentric factors of these factors were computed from correlations available in the simulator. Hydrocarbon and non-hydrocarbon components were lumped into 12 pseudo-components by using the simulator lumping scheme. The EOS was tuned with these pseudo-components by performing regression on the experimental saturation pressure (bubble point), density, viscosity, relative oil volume, formation volume factor, and stock tank oil gravity, using critical properties of the pseudo- $\mathrm{C}_{7}{ }^{+}$components as well as their acentric factors and volume shift factors as regression parameters. Binary interaction coefficients between $\mathrm{CO}_{2}$ and hydrocarbon components were also used as regression parameters.

The fluid model described above was used in Eclipse300 ${ }^{\mathrm{TM}}$, a fully compositional commercial reservoir flow simulator to mimic experimental flue gas displacements, using all physical and fluid saturations' properties. The simulator 
can model important mechanisms of miscible gas injection processes such as vaporization, condensation, and the development of multi-contact miscibility between oil and injected gas.

The compositional simulator accounted for interface mass transfer between all phases present in the flue gas displacement process. The simulator model equations can track the movement of many components constituting the oil-gas system as they move along. It was assumed that thermodynamic equilibrium prevailed at each grid block representing the model during simulation. The distribution of components between the gas and oil phases was obtained by performing flash calculations at each grid block. This enabled the simulator to account for phase behavior effect in a multiphase system.

Another assumption that presumes no mass transfer interaction between the hydrocarbon and water phases was made by [2].

The model equations are solved fully implicitly at every time step in each grid block. Laboratory-determined porosity and absolute permeability were input, and initial water saturation was the same for each grid block. Figure 1 is a workflow of the method we used for the simulation.

\subsection{ECLIPSE Compositional Simulator}

Compositional simulation is ideally suited for; gas injection to increase or maintain

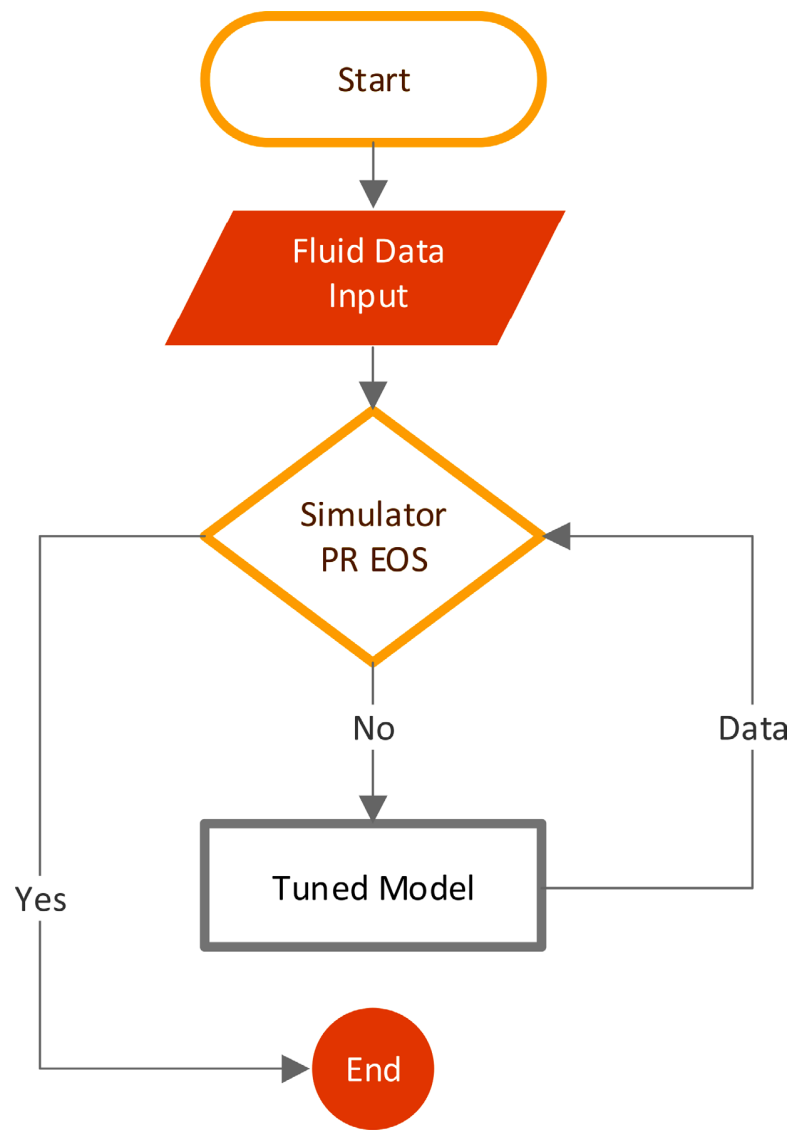

Figure 1. Workflow of the reservoir simulation. 
reservoir pressure, thick reservoirs with a compositional gradient caused by gravity, reservoirs with fluid compositions near bubble point, high-pressure, and high-temperature reservoir modeling, and miscible flooding as the injection gas goes into solution with oil.

ECLIPSE $300^{\mathrm{TM}}$ is a compositional simulator that can be run in fully implicit (IMPES) and adaptive implicit modes (AIM), using a cubic equation of state or pressure dependent K-values. ECLIPSE300 ${ }^{\mathrm{TM}}$ incorporates four equations of state and two additional variations to the PR-EOS. When an equation of state is selected, it is used to obtain Z-factors and phase fugacities and define inter-phase equilibrium and fluid densities. The equations of state available are the Redlich-Kwong, Soave-Redlich-Kwong, Peng-Robinson, and Zudkevitch-Joffe's. ECLIPSE $300^{\mathrm{TM}}$ incorporates four equations of state and two additional variations to the PR equation [16].

In the ECLIPSE program, the required variation of component saturation pressure and liquid density with temperature are obtained using correlations that require the input of the normal boiling point and the reference liquid density at a specified reference temperature [16].

A relevant simulation work has been performed [17]. The authors studied different water injection situations. They looked at the injection of miscible $\mathrm{CO}_{2}$ in water in a two-dimensional, heterogeneous fractured reservoir. Study findings showed that that miscible water alternating $\mathrm{CO}_{2}$ gas injection yielded an incremental oil recovery of $3.95 \%$. Water production has, however, decreased by $3.89 \%$ compared to plain water injection [17].

\section{Results and Discussion}

\subsection{Numerical Simulation}

The PVTi simulator, a component of the Eclipse $300^{\mathrm{TM}}$ platform, was used to tune the PR-EOS to a 10-component fluid system to describe laboratory-measured oil properties and PVT data. The inputs of the simulator for the flash experiment simulation were reservoir temperature and pressure. The percentage mole compositions of $\mathrm{CO}_{2}, \mathrm{C}_{1}$ to $\mathrm{C}_{6}^{+}$and molecular weight of the $\mathrm{C}_{6}^{+}$fraction were entered into the pure component library properties. Density, z-factor, and the critical properties computed by the Lohrenz-Bray-Clark correlation were also input in the simulator.

\subsection{Reservoir Fluid Characterization}

A data bank of fifteen crude oil samples with different compositions were provided by Southern Petroleum Laboratories. Only seven data samples were complete. In these component compositions, API gravities, and molecular weight of $\mathrm{C}_{6}^{+}$fractions were provided.

\subsubsection{Reservoir Fluid Composition}

To investigate the effect of oil composition on estimated MMP, data for ten light oils sampled at different depths from three candidate reservoirs was made avail- 
able. Data from only seven oils was complete and will be used in numerical simulations. Table 1 provides composition data of reservoir fluids A-G.

\subsubsection{Injection Gas Composition}

For each reservoir fluid, flash calculations at different temperatures $\left(200^{\circ} \mathrm{F}\right.$, $288^{\circ} \mathrm{F}$, and $375^{\circ} \mathrm{F}$ ) and at pressures, below the corresponding bubble-point pressure of the oil, were performed. Injection gas was set as flash process separator gas. Table 2 defines injection gas compositions:

\subsubsection{Simulation Model Description}

Fluid models described above were used in a fully compositional reservoir flow simulation package ECLIPSE $300^{\mathrm{TM}}$ to simulate flue gas displacement experiments. The simulator accounts for interface mass transfer between all the phases present in the flue gas displacement process. The simulator model equations can track the movement of components comprising the oil-gas-water system as they move through the porous media. It is assumed that thermodynamic equilibrium exists at each grid block representing the slim tube and reservoir models. Distribution of components between gas and oil phases was obtained by performing flash calculation simulations at each reservoir condition. This allows the compositional model to account for the phase behavior effect in a multiphase system and the calculation of phase densities, viscosities, and interfacial tension. Results of the flash calculation showed no distribution between the oil and gas phases;

Table 1. Oil sample compositions (reported by southern petroleum laboratories).

\begin{tabular}{cccccccc}
\hline Sample & A & B & C & D & E & F & G \\
\hline API Gravity & 37.3 & 39.7 & 40.9 & 36.0 & 41.3 & 37.0 & 40.9 \\
CO $_{2}$ & 0.06 & 0.0 & 0.054 & 0.0 & 0.0 & 0.0 & 0.0 \\
$\mathrm{C}_{1}$ & 0.724 & 0.873 & 0.651 & 0.860 & 0.989 & 0.902 & 0.88 \\
$\mathrm{C}_{2}$ & 1.911 & 1.746 & 1.934 & 2.774 & 2.104 & 2.910 & 1.712 \\
$\mathrm{C}_{3}$ & 5.553 & 5.561 & 5.982 & 6.798 & 5.916 & 7.234 & 4.88 \\
i-C & 2.133 & 2.277 & 2.404 & 1.856 & 2.266 & 1.906 & 1.808 \\
n- $C_{4}$ & 5.835 & 6.263 & 6.633 & 6.154 & 6.114 & 6.557 & 4.832 \\
i- $C_{5}$ & 3.541 & 3.815 & 3.741 & 3.008 & 3.578 & 3.156 & 2.912 \\
n- ${ }_{5}$ & 4.427 & 4.612 & 4.536 & 4.044 & 4.388 & 4.262 & 3.600 \\
$\mathrm{C}_{6}^{+}$ & 75.816 & 74.853 & 74.065 & 74.506 & 74.645 & 73.073 & 79.376 \\
M.W. & 247.53 & 234.56 & 224.38 & 243.80 & 222.17 & 260.61 & 187.30 \\
\hline
\end{tabular}

Table 2. Injection gas composition.

\begin{tabular}{ccc}
\hline Component & Flue Gas, FG-1 & Flue Gas, FG-2 \\
\hline $\mathrm{N}_{2}$ & 0.85 & 0.70 \\
$\mathrm{CO}_{2}$ & 0.15 & 0.30 \\
\hline
\end{tabular}


there was no gas phase composition for any of the oil samples.

\subsubsection{Slim Tube Experiment Simulation}

To simulate flow and phase behavior in a conventional slim tube, the soft experiments were modeled using a 200-grid block system. This number of grid blocks was arrived at based on sensitivity study on pressure variation with grid block dimension. Porosity and absolute permeability values in the slim tube were used according to available data from literature. Gas-oil capillary pressure was negligible and functional relationships for oil-water and gas-oil systems were assumed to be as follows in Equations (1)-(4):

For the oil-water system,

$$
\begin{gathered}
k_{r w}=k_{r w o}\left(\frac{S_{w}-S_{w o r}}{1-S_{\text {oirw }}-S_{w r r}}\right)^{N_{w}}, \\
k_{\text {row }}=k_{\text {rocw }}\left(1-\frac{S_{w}-S_{\text {wocn }}}{1-S_{\text {woon }}-S_{\text {orw }}}\right)^{N_{\text {ow }}}
\end{gathered}
$$

For the gas-oil system,

$$
\begin{gathered}
k_{r g}=k_{r g o}\left(\frac{S_{g}-S_{g c r}}{1-S_{g c r}-S_{\text {oirg }}-S_{\text {wcon }}}\right)^{N_{g}}, \\
k_{\text {rog }}=k_{\text {rocg }}\left(1-\frac{S_{g}-S_{g o c n}}{1-S_{\text {org }}-S_{\text {wcon }}-S_{g c o n}}\right)^{N_{o w}}
\end{gathered}
$$

Table 3 summarizes parameters used for the one dimensional slim-tube displacement soft experiments.

Slim tube displacements using injection pressures ranging from 2000 psia to 3600 psia for oil samples A to G were conducted for gases FG-1 and FG-2. These experiments were conducted under three conditions of temperature and pressure for each flue gas composition. The oil samples were characterized as

Table 3. Parameters for one-dimensional simulation of slim tube displacement.

\begin{tabular}{cc}
\hline Type of grid block: & Cartesian \\
\hline Number of grid blocks in x-direction: & 200 \\
Number of grid blocks in y-direction: & 1 \\
Number of grid blocks in z-direction: & 1 \\
Length of slim tube: & $10 \mathrm{~m}$ \\
Permeability: & $2000 \mathrm{md}$ \\
Porosity: & $10 \%$ \\
Water saturation: & $0 \%$ \\
Flue gas injection: & Pressure controlled \\
Temperature: & $200^{\circ} \mathrm{F}, 288^{\circ} \mathrm{F}, 375^{\circ} \mathrm{F}$ \\
Pressure: & $2000,2600,3200 \mathrm{psi}$ \\
\hline
\end{tabular}


mentioned earlier by the PR-EOS and used in the flow simulator to replicate slim tube displacements. Critical properties of oils obtained from flash calculation as well as binary interaction coefficients, reservoir conditions of temperature and pressure, liquid and vapor fractions of the oil samples, rock properties, saturations, injection pressures, and run time were all input into the data file. The fore-mentioned factors were all kept constant for each sample except for the injection pressure. The data file was run in the ECLIPSE simulator and results were read from the summary files obtained at the end of each simulation run.

At MMP, local displacement efficiency is reported to approach $100 \%$. Miscibility can be achieved at injection, at gas-oil front or somewhere in between, miscibility allows a complete displacement of reservoir fluid. Table 4 summarizes oils MMPs for slim tube soft experiments at prescribed reservoir in-situ conditions. These in-situ conditions portray pressure and temperature brackets of candidate reservoirs for miscible flue gas injection.

Oil production totals at the beginning and at the end of the slim tube displacement soft experiments are read from the Eclipse summary files. Recovery is defined as the ratio between oil volume produced and the oil volume fed to the slim tube, the sequence is repeated for several pressures, and recovery is recorded for each pressure. The recovery factor was then plotted against each injection pressure to determine the minimum miscibility pressure. Figure 2 shows the recoveries for sample $\mathrm{A}$, as a function of injection pressures. MMP is the inflection point on each curve. Figure 3 indicates that there is no significant oil recovery at pressures higher than MMPs.

\subsubsection{Field-Scale Simulation Miscibility Performance}

Injection of cost-effective flue gases could be employed in reservoirs where a favorable combination of pressure, reservoir characteristics and fluid properties make the gas injection project a competitive process compared to other secondary oil recovery methods. However, for a gas injection project to be competitive, several conditions should be satisfied. The incremental oil recovery is largely

Table 4. MMP for flue slim tube simulations.

\begin{tabular}{|c|c|c|c|c|c|c|}
\hline \multirow[b]{2}{*}{ Sample } & \multicolumn{2}{|c|}{$\left(200^{\circ} \mathrm{F}, 2000 \mathrm{psi}\right)$} & \multicolumn{2}{|c|}{$\left(288^{\circ} \mathrm{F}, 2600 \mathrm{psi}\right)$} & \multicolumn{2}{|c|}{$\left(375^{\circ} \mathrm{F}, 3200 \mathrm{psi}+\right)$} \\
\hline & $\begin{array}{c}\text { FG-1 } \\
\text { MMP (psi) }\end{array}$ & $\begin{array}{c}\text { FG-2 } \\
\text { MMP (psi) }\end{array}$ & $\begin{array}{c}\text { FG-1 } \\
\text { MMP (psi) }\end{array}$ & $\begin{array}{c}\text { FG-2 } \\
\text { MMP (psi) }\end{array}$ & $\begin{array}{c}\text { FG-1 } \\
\text { MMP (psi) }\end{array}$ & $\begin{array}{c}\text { FG-2 } \\
\text { MMP (psi) }\end{array}$ \\
\hline A & 2900 & 2200 & 2800 & 2740 & 3300 & 3250 \\
\hline B & 2600 & 2200 & 2720 & 2700 & 3300 & 3240 \\
\hline $\mathrm{C}$ & 2400 & 2400 & 2700 & 2700 & 3300 & 3250 \\
\hline $\mathrm{D}$ & 2600 & 2250 & 2800 & 2700 & 3300 & 3250 \\
\hline $\mathrm{E}$ & 2400 & 2400 & 2700 & 2700 & 3300 & 3250 \\
\hline $\mathrm{F}$ & 2150 & 2100 & 2800 & 2700 & 3300 & 3250 \\
\hline G & 2200 & 2200 & 2700 & 2650 & 3300 & 3270 \\
\hline
\end{tabular}




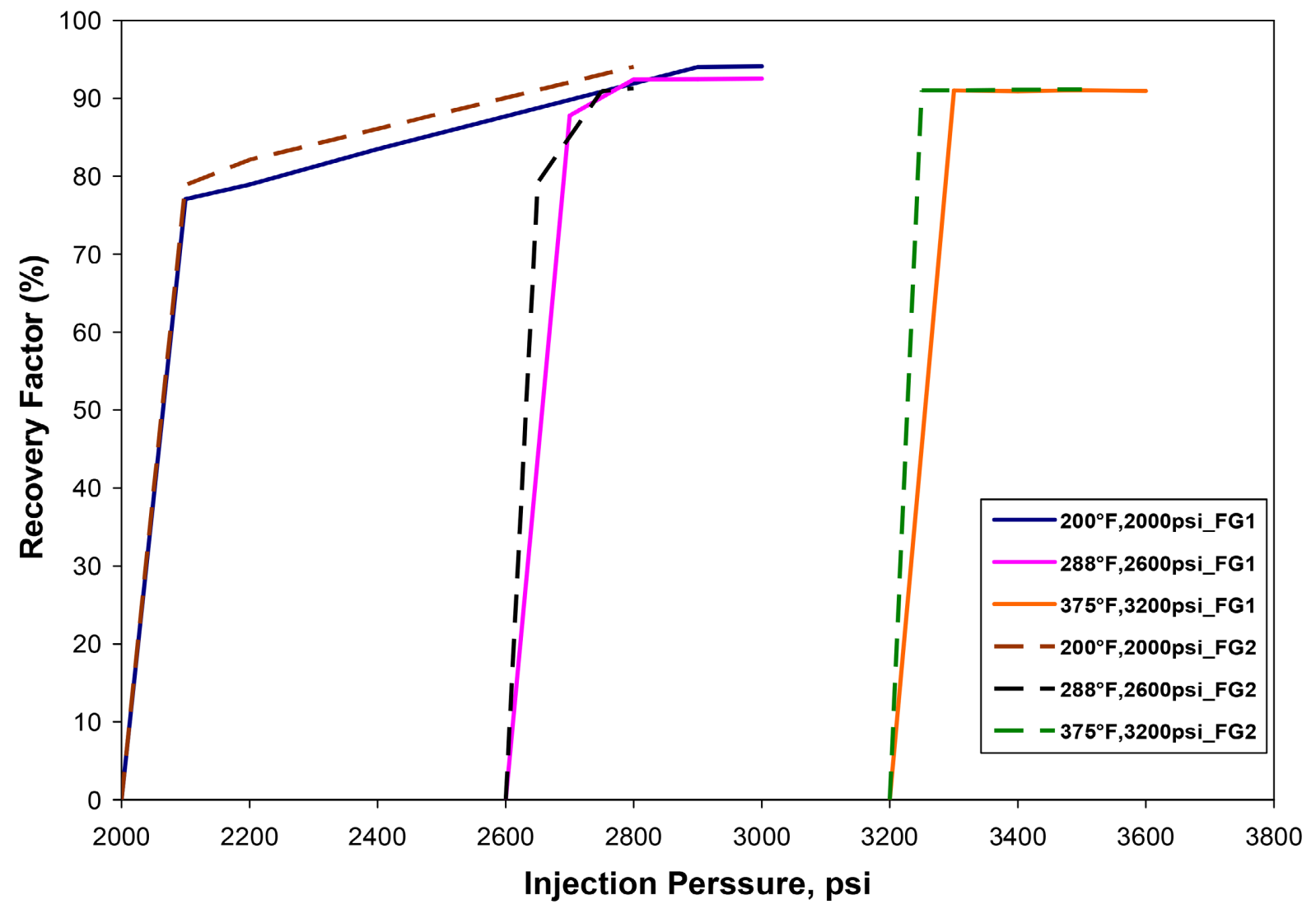

Figure 2. Slim tube recovery and injection pressure for sample A at $37.3^{\circ} \mathrm{API}$.

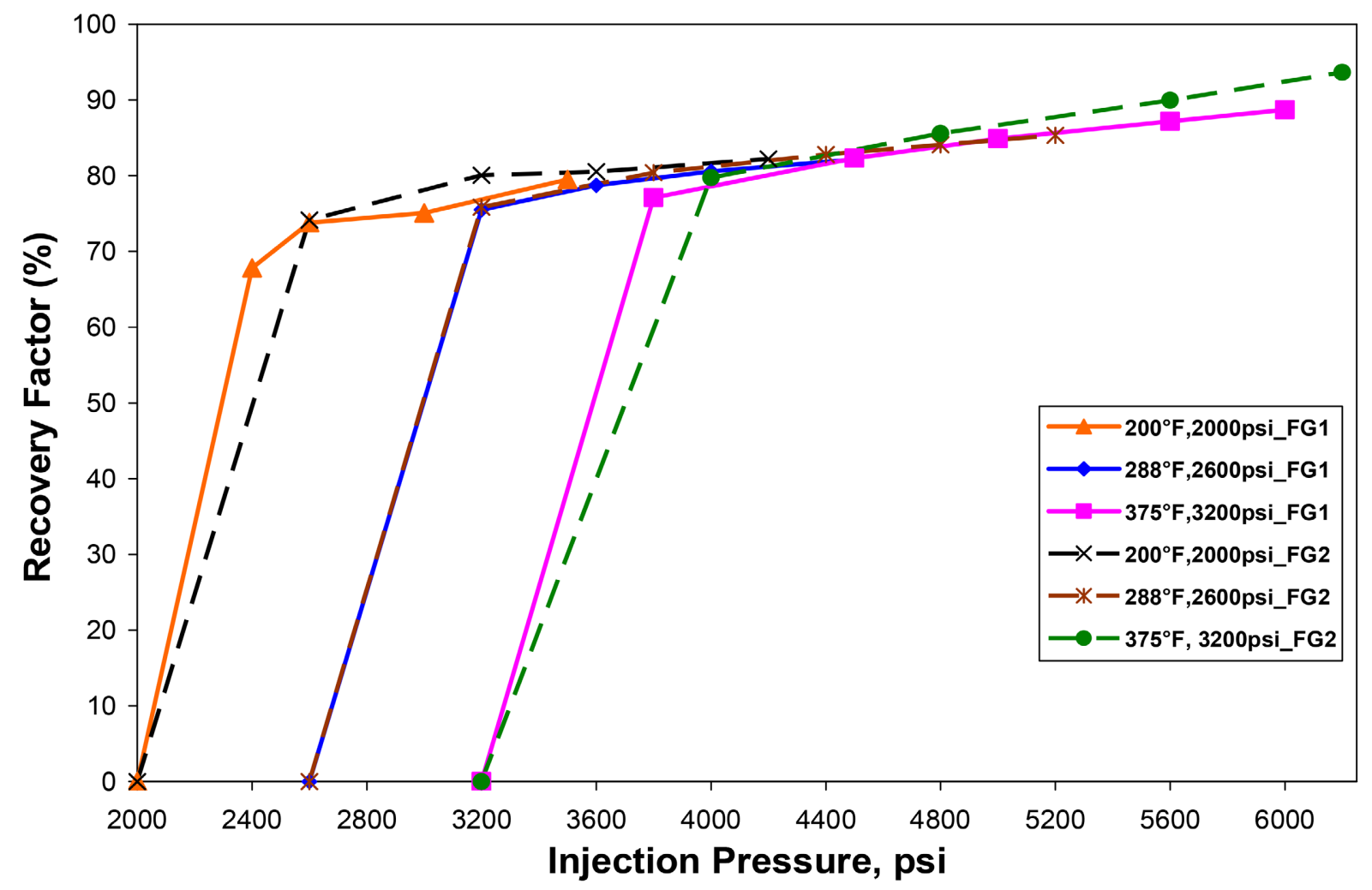

Figure 3. Field-scale recovery factor and injection pressure for sample A, $37.3^{\circ} \mathrm{API}$. 
dependent on injection pressure, reservoir characteristics and fluid properties such as homogeneity, capillarity, gravity segregation. A parametric study is done, using a compositional simulator to analyze the effect of such important parameters on miscible performance recovery from a conceptual reservoir.

\subsubsection{Field-Scale Simulation Description}

Description of the conceptual model is summarized in Table 5. Adaptive implicit solution avoids the time step restrictions imposed by small blocks and minimizes the computational expense of a fully implicit solution. The layers in the model are homogenous and of constant porosity, permeability, and thickness. Saturation and PVT data of the reservoir fluid are also provided in Table 5. Reservoir conditions of temperature and pressure considered are the same as in the case of the slim tube displacement experiments. Same reservoir fluids are used; however, flash experiments are re-run using field data. Reservoir oil gravities are as depicted in Table 1 . Water viscosity is taken as $0.56 \mathrm{cp}$ at initial reservoir conditions. Initial oil and water saturations are set at 0.85 and 0.15 , respectively. Flue gases have the same compositions given in Table 1.

Table 6 is a summary of field-scale MMPs. These MMPs are found to be larger than the MMPs determined from slim tube soft experiments.

Figure 4 shows recovery factor as a function of injection pressure for the 3 different reservoirs using FG-1 and FG-2 for oil sample A with an API gravity of $37.3^{\circ}$. In this case, injection pressure was increased past beyond 6000 psia.

Table 5. Reservoir grid data.

\begin{tabular}{|c|c|c|c|c|c|}
\hline \multicolumn{6}{|c|}{$\mathrm{NX}=100, \mathrm{NY}=1, \mathrm{NZ}=5$} \\
\hline \multicolumn{6}{|c|}{$\mathrm{DX}=40, \mathrm{DY}=1000, \mathrm{DZ}=41$} \\
\hline \multicolumn{3}{|l|}{ Porosity } & \multicolumn{3}{|c|}{0.18} \\
\hline \multicolumn{3}{|c|}{ Datum (subsurface), $\mathrm{ft}$} & \multicolumn{3}{|l|}{8073} \\
\hline \multicolumn{3}{|c|}{ Water-oil Contact, $\mathrm{ft}$} & \multicolumn{3}{|l|}{10,000} \\
\hline \multicolumn{3}{|c|}{ Gas-oil Contact, $\mathrm{ft}$} & \multicolumn{3}{|l|}{8000} \\
\hline \multicolumn{3}{|c|}{ Capillary pressure at contact, psi } & \multicolumn{3}{|l|}{0} \\
\hline \multicolumn{3}{|l|}{ Oil Saturation } & \multicolumn{3}{|l|}{$85 \%$} \\
\hline$P(p s i)$ & $\mathrm{T}\left({ }^{\circ} \mathrm{F}\right)$ & \multicolumn{2}{|c|}{ Permeability (mD) } & Thickness (ft) & Depth to top (ft) \\
\hline 2000 & 200 & 0.5 & 30 & 41 & 8268 \\
\hline 2600 & 288 & 60 & 150 & 41 & 8268 \\
\hline 3200 & 375 & 90 & & 41 & 8268 \\
\hline \multicolumn{6}{|c|}{ Water Properties } \\
\hline \multicolumn{4}{|c|}{ Compressibility $\left(\mathrm{psi}^{-1}\right)$} & \multicolumn{2}{|c|}{$3.2792 \times 10^{-6}$} \\
\hline \multicolumn{4}{|l|}{ Density $\left(\mathrm{lb} / \mathrm{ft}^{3}\right)$} & \multicolumn{2}{|c|}{62.4280} \\
\hline \multicolumn{4}{|l|}{ Viscosity (cp) } & \multicolumn{2}{|c|}{0.56} \\
\hline \multicolumn{4}{|c|}{ Rock Compressibility $\left(\mathrm{psi}^{-1}\right)$} & \multicolumn{2}{|c|}{$4.0 \times 10^{-6}$} \\
\hline
\end{tabular}


Table 6. Minimum miscibility pressure of field-scale simulations.

\begin{tabular}{|c|c|c|c|c|c|c|}
\hline \multirow[b]{2}{*}{ Sample } & \multicolumn{2}{|c|}{$200^{\circ} \mathrm{F}, 2000$ psia } & \multicolumn{2}{|c|}{$288^{\circ} \mathrm{F}, 2600$ psia } & \multicolumn{2}{|c|}{$375^{\circ} \mathrm{F}, 3200$ psia } \\
\hline & $\begin{array}{c}\text { MMP FG-1 } \\
\text { (psia) }\end{array}$ & $\begin{array}{c}\text { MMP FG-2 } \\
\text { (psia) }\end{array}$ & $\begin{array}{c}\text { MMP FG-1 } \\
\text { (psia) }\end{array}$ & $\begin{array}{c}\text { MMP FG-2 } \\
\text { (psia) }\end{array}$ & $\begin{array}{c}\text { MMP FG-1 } \\
\text { (psia) }\end{array}$ & $\begin{array}{c}\text { MMP FG-2 } \\
\text { (psia) }\end{array}$ \\
\hline $\mathrm{A}$ & 3020 & 2600 & 3200 & 3200 & 4480 & 4000 \\
\hline $\mathrm{B}$ & 2600 & 2500 & 3700 & 3600 & 4500 & 4000 \\
\hline $\mathrm{C}$ & 3500 & 3000 & 3600 & 3580 & 3980 & 3800 \\
\hline $\mathrm{D}$ & 2960 & 2700 & 3600 & 3080 & 4000 & 3800 \\
\hline $\mathrm{E}$ & 3020 & 2600 & 3520 & 3200 & 4000 & 3940 \\
\hline $\mathrm{F}$ & 3200 & 3000 & 3600 & 3220 & 4500 & 4000 \\
\hline G & 3000 & 2960 & 3680 & 3240 & 4520 & 4400 \\
\hline
\end{tabular}

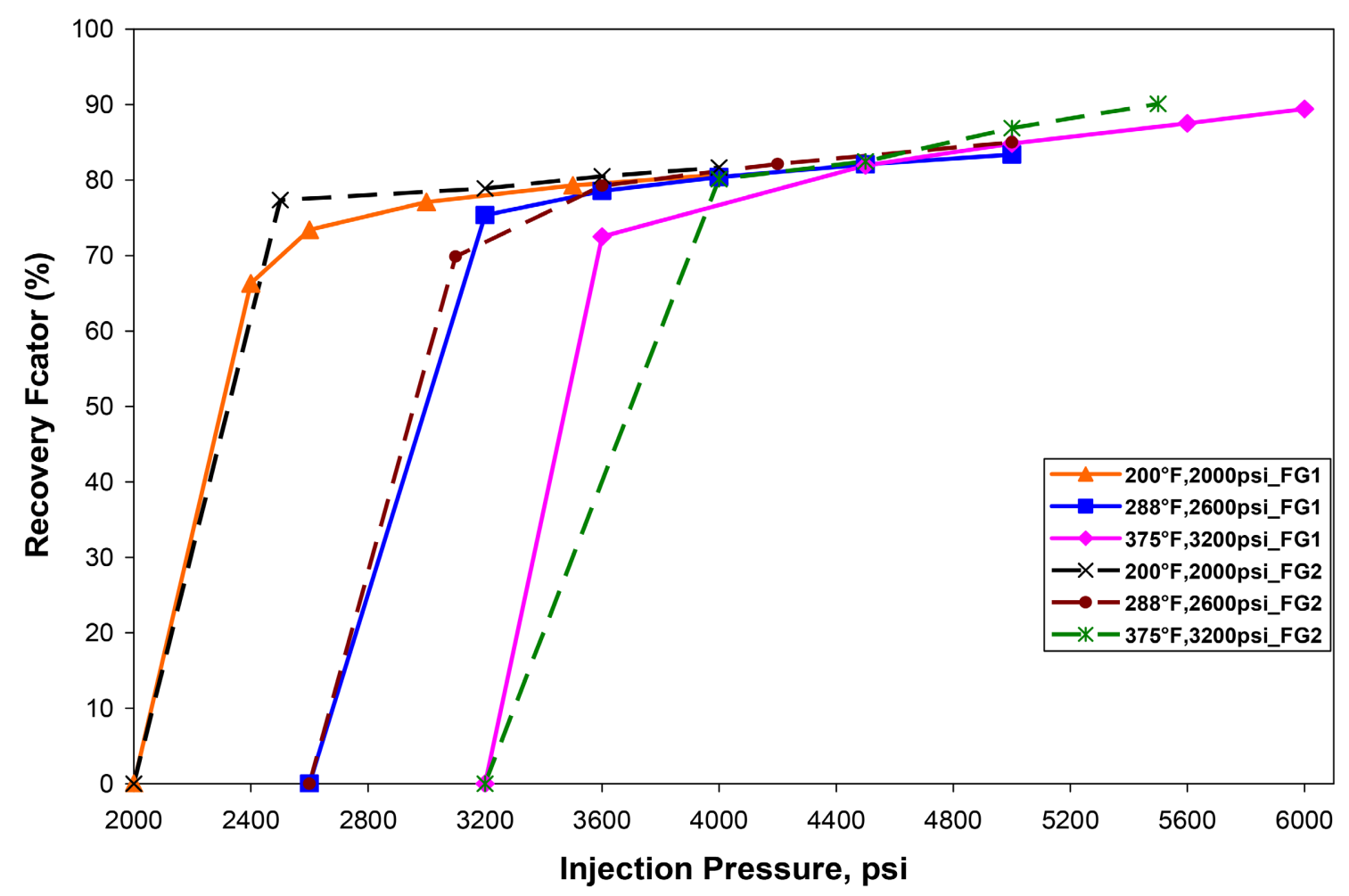

Figure 4. Field-scale recovery factor and injection pressure for sample B, $39.7^{\circ}$ API.

Figure 4 portrays field-scale recovery as a function of injection pressure for sample B with an API gravity of $39.7^{\circ}$. Predicted MMPs are also extracted from the curves' inflection points.

\section{Comparison of Simulation and Correlation Results}

Numerical simulation calculations for injected gas/oil systems utilize the PR-EOS; an equation that is consistent and that can be easily tuned to available experimental data.

Figures 5-7 compare predicted MMPs for samples A-G. It is important to 


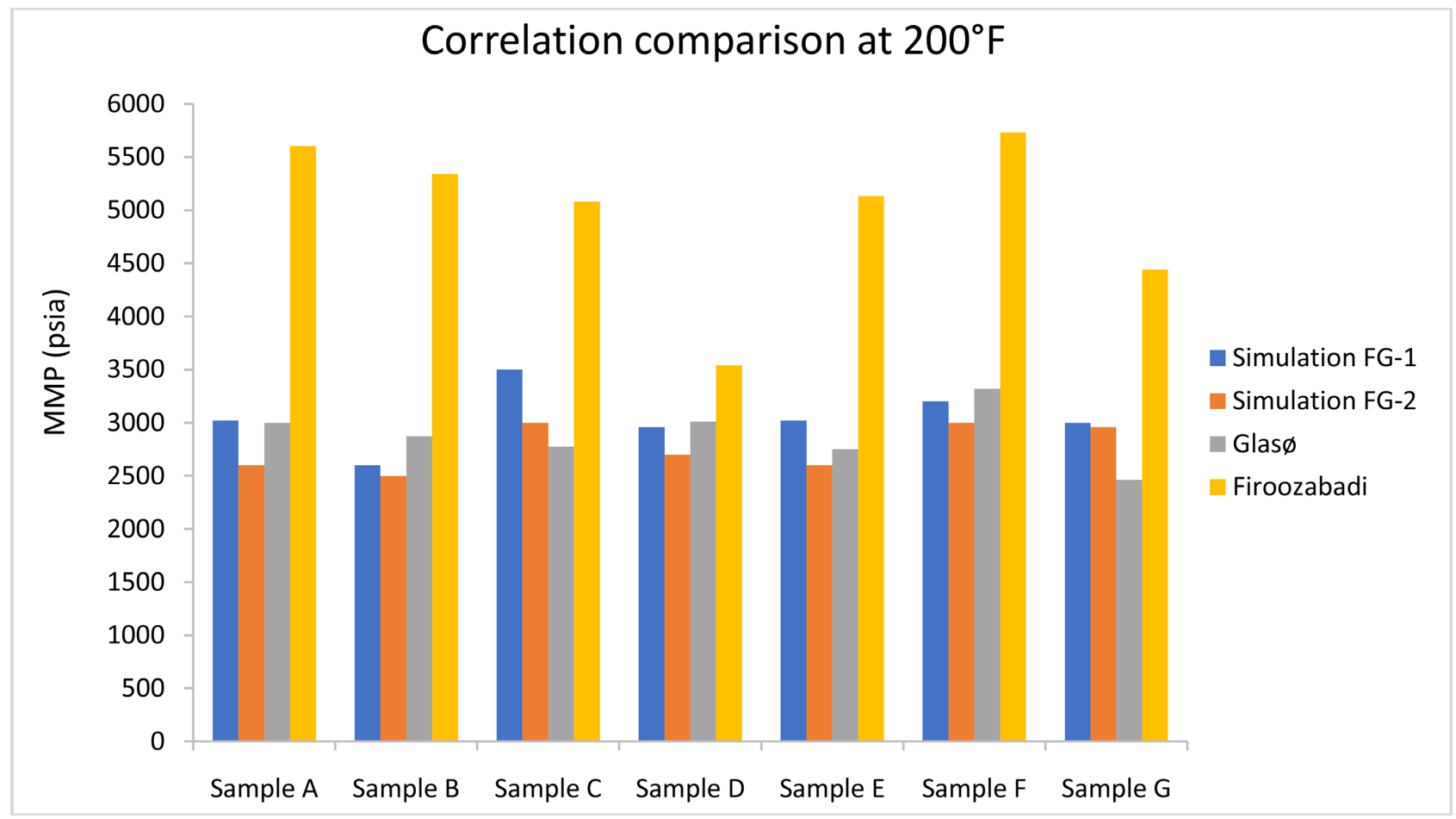

Figure 5. Comparison of MMP correlations and simulation at $200^{\circ} \mathrm{F}$.

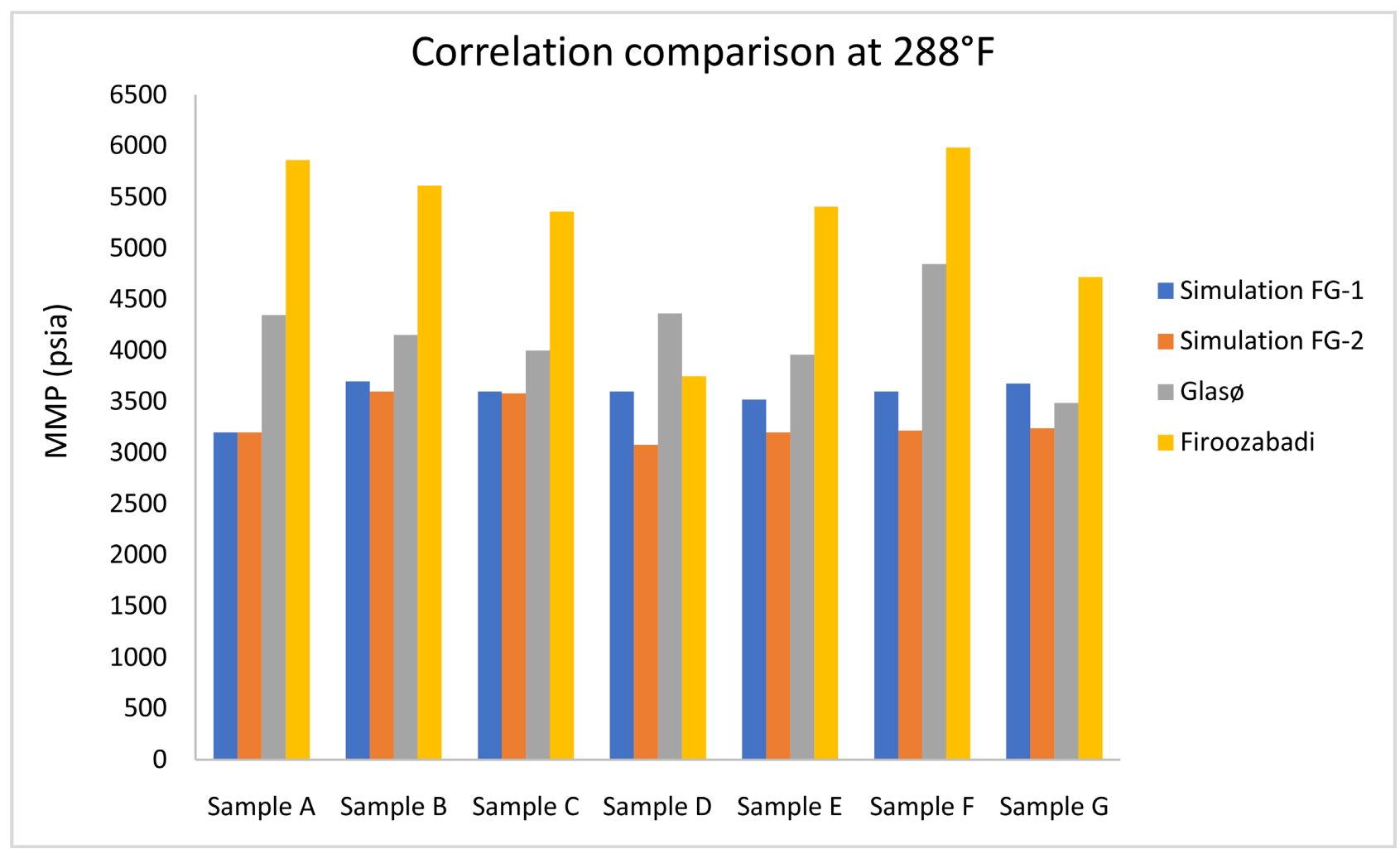

Figure 6. Comparison of MMP correlations and simulation at $288^{\circ} \mathrm{F}$.

note that Glasø's correlation, developed for North Sea oil from experimental slim tube experiments, accounts for molecular weight and temperature and does 
not depend on mole percent of intermediates. Its predicted results compare well with the simulation results. The discrepancy in the results can be attributed to the fact that Glasø's correlation does not account for mole percent of intermediates. Results from the Firoozabadi's correlation; however, are on the higher side since the correlation did not consider temperature; a significant factor in the miscibility mechanism.

Figure 6 also indicates that Firoozabadi's MMP values are on the high side. On the other hand, Glasø's predicted MMPs are comparable to the simulation results for both FG-1 and FG-2. Though, a larger discrepancy is depicted for sample F.

Figure 7 compares results for the third reservoir with an average in-situ temperature of $375{ }^{\circ} \mathrm{F}$. At this temperature, Firoozabadi's predicted MMPs align better with Glasø's predictions except for sample D.

\subsection{Comparison of Slim Tube and Field-scale MMPs}

Results of the slim tube displacement and field-scale soft experimentations are presented in Figures 8-10. These figures indicate that predicted field-scale MMPs are higher than MMPs predicted from slim tube displacements, for all the seven oil samples.

Figure 9 indicates that MMP values for FG-1 $\left(15 \% \mathrm{~N}_{2}\right)$ for both field-scale and slim tube experiments are on the high side. This is consistent with published data since MMP increases with lower $\mathrm{CO}_{2}$ content.

At high temperature, $\mathrm{T}=375^{\circ} \mathrm{F}$, Figure 10 indicates that predicted MMP values for both experiments are on the low side. This agrees with literature since

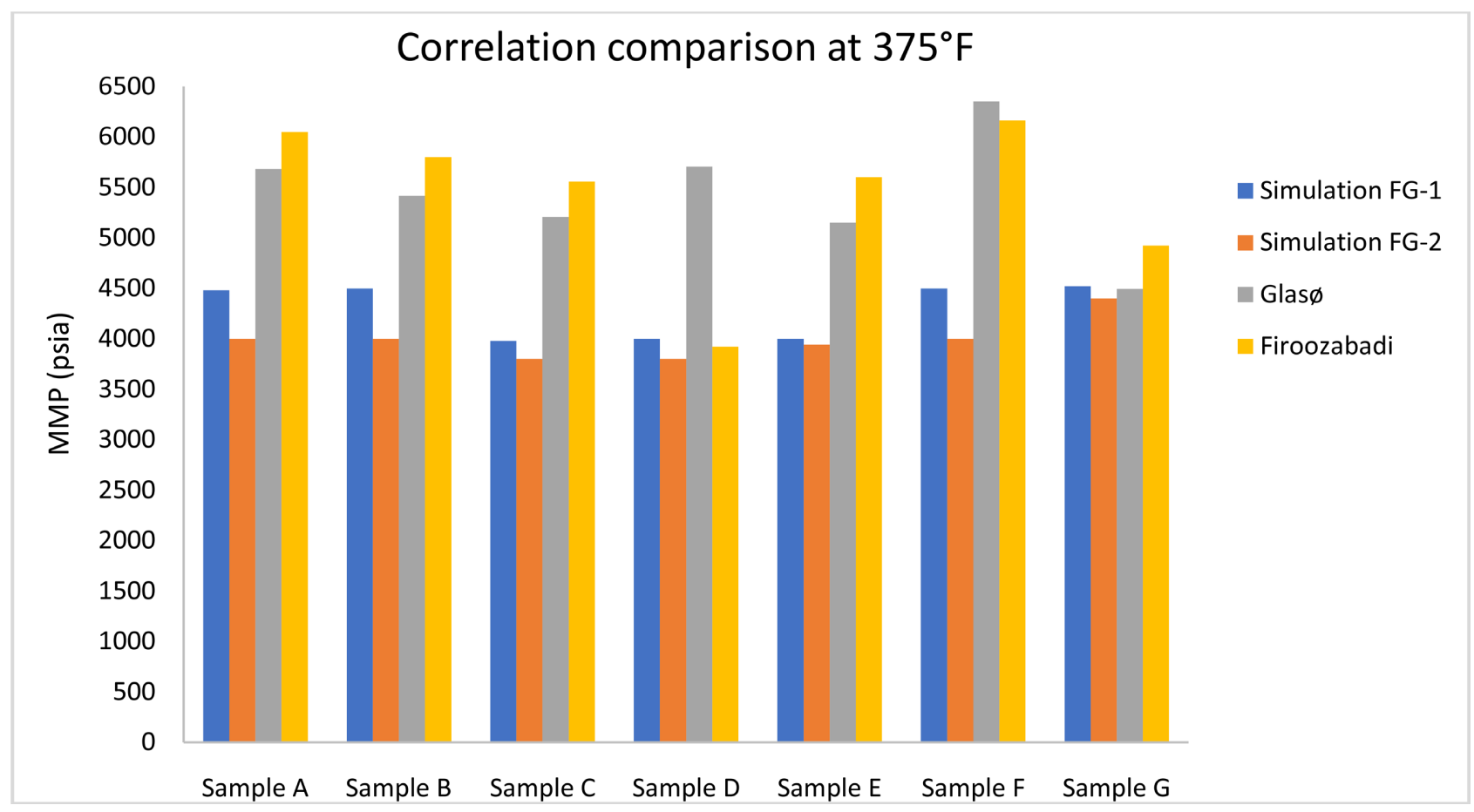

Figure 7. Comparison of MMP correlations and simulation at $375^{\circ} \mathrm{F}$. 


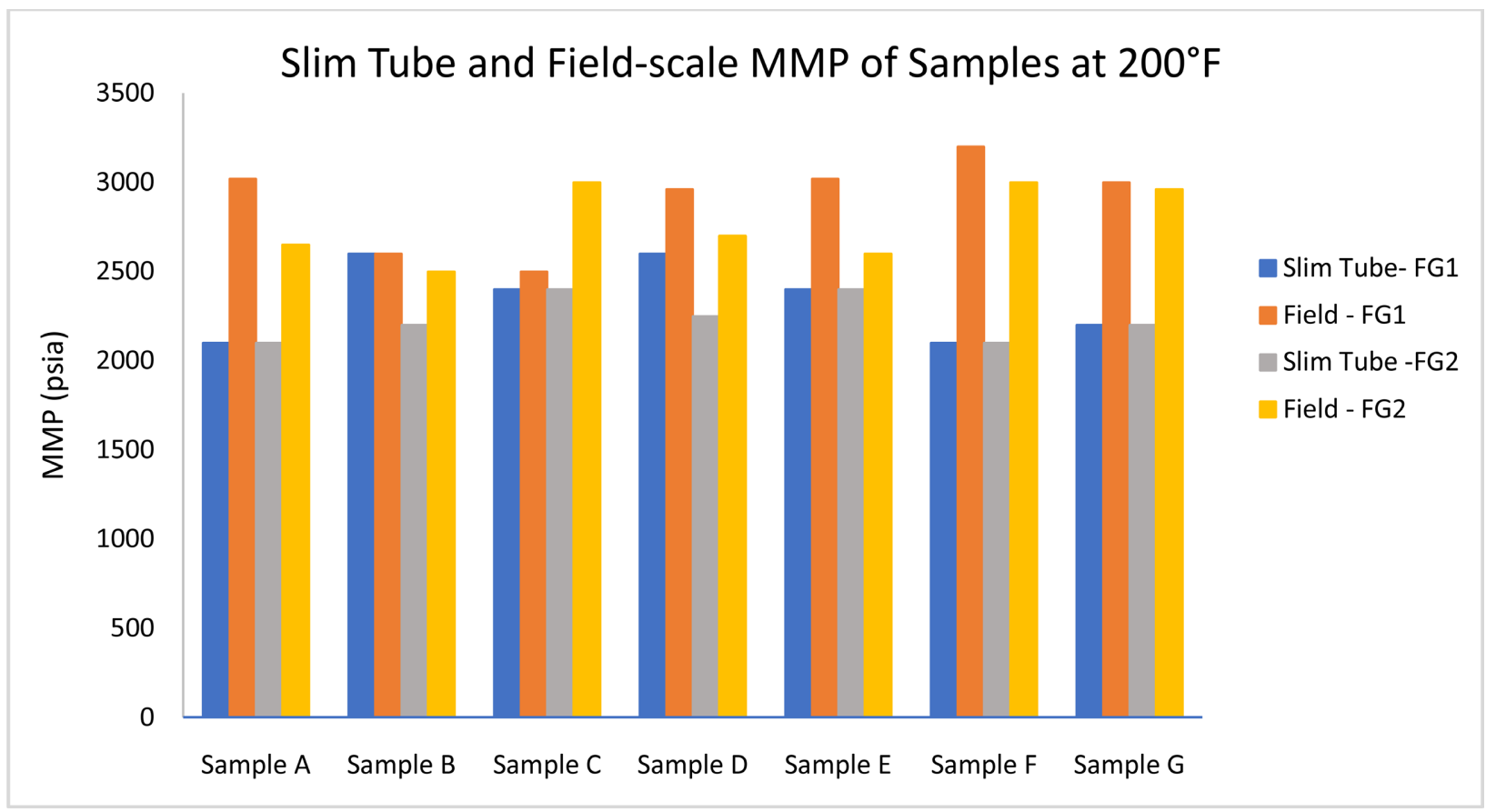

Figure 8. Slim tube and field-scale MMP of samples at $200^{\circ} \mathrm{F}$.

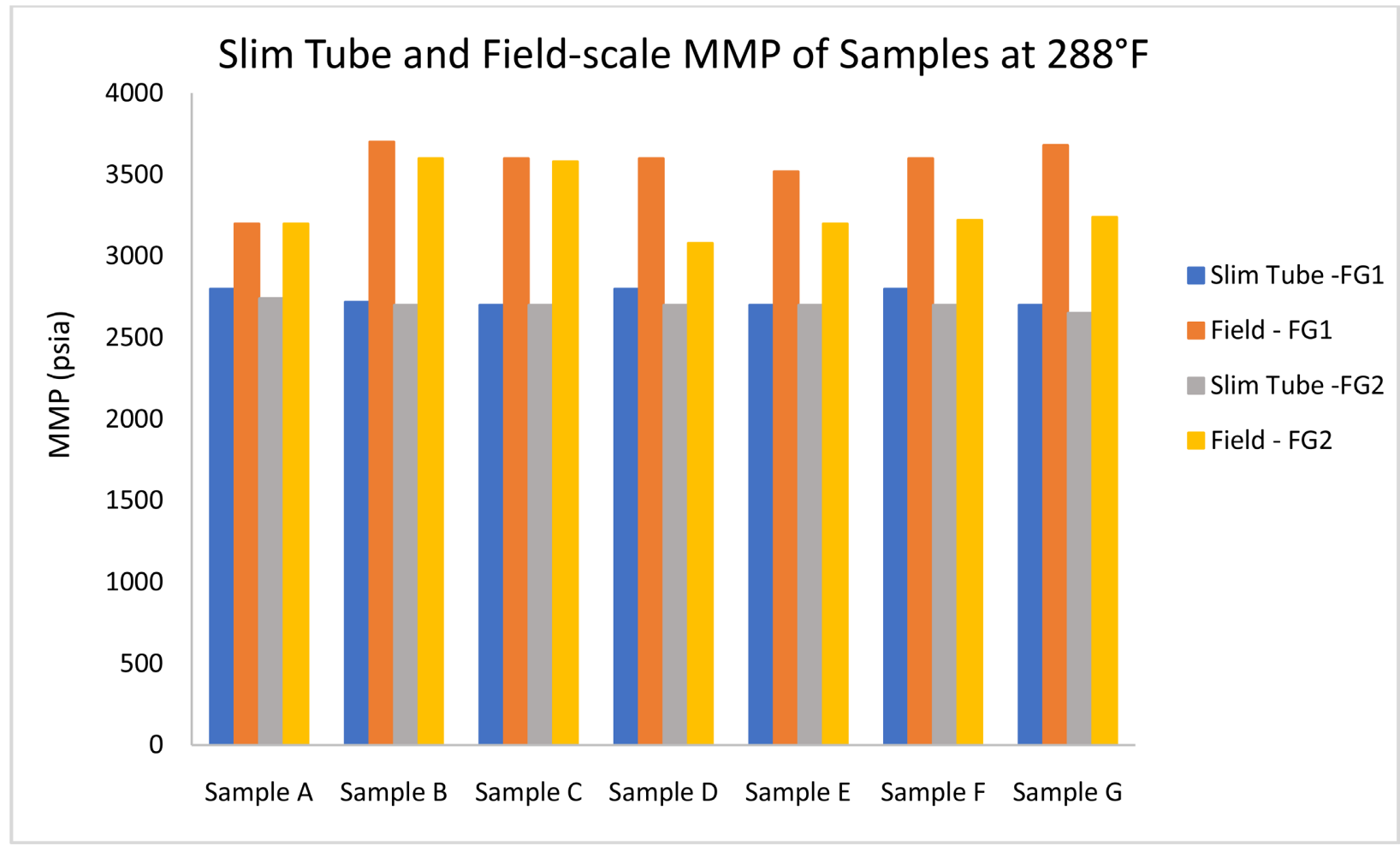

Figure 9. Slim tube and field-scale MMP of samples at $288^{\circ} \mathrm{F}$.

MMP decreases with increasing temperature and increasing $\mathrm{CO}_{2}$ content.

\subsection{Oil Recovery Performance}

Recoveries obtained during slim tube and field-scale displacement simulations 
are summarized in Table 7 and Table 8. These recoveries reflect cumulative oil produced at predicted MMPs. Tables also indicate that increased $\mathrm{CO}_{2}$ content from $15 \%$ to $30 \%$ yielded a slight increase in the recovery factor. The trend is the same across the board for all the seven samples at different in-situ conditions. The increased oil recovery is a direct result of $\mathrm{CO}_{2}$ dissolution in oil. Such mechanism leads to oil phase swelling and in turn a reduction in oil viscosity and enhances production.

Recoveries from slim tube experiments (Table 7) are higher than those obtained from field-scale simulations (Table 8). Recoveries vary from a low of 88.7 for sample $\mathrm{G}$ and FG-1 (15\% $\left.\mathrm{CO}_{2}\right)$ to a high of $94.35 \%$ for sample A and FG-2 $\left(30 \% \mathrm{CO}_{2}\right)$.

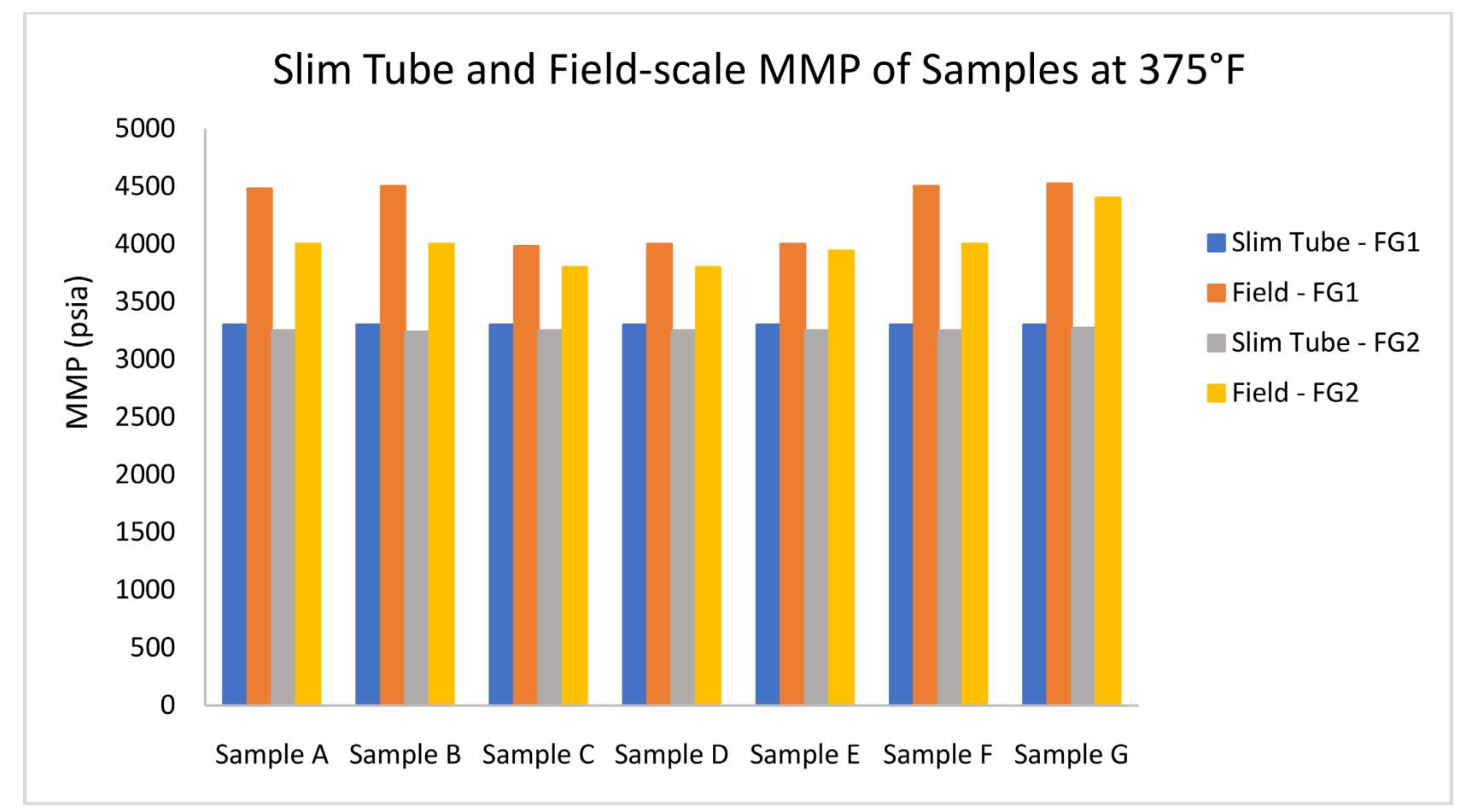

Figure 10. Slim tube and field-scale MMP of samples at $375^{\circ} \mathrm{F}$.

Table 7. Recovery factor for slim tube simulations.

\begin{tabular}{ccccccc}
\hline \multirow{2}{*}{ Sample } & \multicolumn{2}{c}{$\left(\mathbf{2 0 0}{ }^{\circ} \mathrm{F}, \mathbf{2 0 0 0} \mathrm{psia}\right)$} & \multicolumn{2}{c}{$\left(\mathbf{2 8 8}^{\circ} \mathrm{F}, \mathbf{2 6 0 0} \mathrm{psia}\right)$} & \multicolumn{2}{c}{$\left(\mathbf{3 7 5}{ }^{\circ} \mathrm{F}, \mathbf{3 2 0 0} \mathrm{psia}\right)$} \\
\cline { 2 - 7 } & RF (FG-1) & RF (FG-2) & RF (FG-1) & RF (FG-2) & RF (FG-1) & RF (FG-2) \\
\hline A & 94.14 & 94.35 & 92.56 & 92.58 & 90.95 & 91.16 \\
B & 93.25 & 93.45 & 91.72 & 91.86 & 90.10 & 90.75 \\
C & 92.48 & 92.68 & 91.06 & 91.66 & 89.47 & 90.02 \\
D & 89.40 & 93.53 & 91.65 & 91.95 & 90.28 & 90.83 \\
E & 92.53 & 92.76 & 91.11 & 92.46 & 89.36 & 90.19 \\
F & 91.07 & 93.87 & 92.12 & 92.17 & 90.60 & 90.89 \\
G & 91.88 & 92.24 & 90.73 & 90.86 & 88.70 & 89.20 \\
\hline
\end{tabular}


Table 8. Recovery factor for field-scale simulations.

\begin{tabular}{ccccccc}
\hline \multirow{2}{*}{ Sample } & \multicolumn{2}{c}{$\left(\mathbf{2 0 0 ^ { \circ } \mathrm { F } , 2 0 0 0 \mathrm { psia } )}\right.$} & \multicolumn{2}{c}{$\left(288^{\circ} \mathrm{F}, \mathbf{2 6 0 0} \mathrm{psia}\right)$} & \multicolumn{2}{c}{$\left(375^{\circ} \mathrm{F}, 3200\right.$ psia $)$} \\
\cline { 2 - 7 } & RF (FG-1) & RF (FG-2) & RF (FG-1) & RF (FG-2) & RF (FG-1) & RF (FG-2) \\
\hline A & 80.88 & 82.22 & 83.31 & 85.33 & 88.72 & 92.84 \\
B & 80.69 & 81.69 & 83.39 & 85.71 & 89.44 & 93.61 \\
C & 79.19 & 80.58 & 82.70 & 85.29 & 89.55 & 93.60 \\
D & 80.93 & 81.63 & 82.10 & 84.69 & 87.46 & 90.19 \\
E & 80.31 & 81.46 & 83.40 & 85.97 & 90.23 & 94.01 \\
F & 80.94 & 82.71 & 82.88 & 84.59 & 87.47 & 89.40 \\
G & 79.05 & 82.89 & 84.33 & 88.24 & 94.93 & 98.08 \\
\hline
\end{tabular}

Table 8 displays recovery factors for field-scale simulations. Values are lower than those obtained from slim tube experiments, since field-scale better mimic fluid flow in porous media and simulate miscibility displacement.

\section{Conclusions}

Benefits of two flue gases; one with a $0.15 / 0.85 \mathrm{CO}_{2} / \mathrm{N}_{2}$ ratio and another with a $0.30 / 0.70 \mathrm{CO}_{2} / \mathrm{N}_{2}$ ratio are addressed on three miscible flooding candidate reservoirs in South Louisiana. MMPs needed to be estimated for screening purposes. We used soft experimentations to estimate MMPs and recovery factors. Predicted MMPs were compared to proper correlations, Glasø's and Foroozabadi's. This study's predicted MMPs align more with values estimated using the Glasø's correlation. On the other hand, predicted MMPs differ from those projected using the Firoozabadi's correlation. It was also concluded that increased $\mathrm{CO}_{2}$ content in the flue gas resulted in lower MMPs and higher recoveries.

It was similarly established that MMPs predicted using field-scale simulations are lower than those estimated using slim tube soft experimentations and that field-scale is a better predictor since it better describes fluid flow in porous media and can be used to mimic miscibility mechanisms.

It is also suggested to use soft experimentations to replace expensive laboratory experiments since field-scale simulations results were reliable and compare well with industry-standard empirical models.

Future work will involve the use of data analysis, data analytics and data training in the development of an empirical equation that can predict MMP. The model data bank is generated from soft experimentations using Eclipse simulation platform.

\section{Acknowledgements}

Not applicable.

\section{Availability of Data and Materials}

The data supporting the conclusions of this paper are included within the paper. 
Any queries regarding these data may be directed to the corresponding author.

\section{Consent for Publication}

Authors have agreed to submit it in its current form for publication in the journal.

\section{Ethics Approval and Consent to Participate}

Not applicable.

\section{Funding}

This research was not funded.

\section{Conflicts of Interest}

The authors declare no conflicts of interest regarding the publication of this paper.

\section{References}

[1] Srivastava, R.K., Huang, S.S. and Dong, M. (1999) Comparative Effectiveness of $\mathrm{CO}_{2}$ Produced Gas, and Flue Gas for Enhanced Heavy-Oil Recovery. SPE Reservoir Evaluation \& Engineering, 2, 238-247. https://doi.org/10.2118/56857-PA

[2] Shokoya, O.S., Mehta, S.A., Moore, R.G., Maini, B.B., Pooladi-Darvish, M. and Chakma, A. (2004) The Mechanism of Flue Gas Injection for Enhanced Light Oil Recovery. Journal of Energy Resources Technology, 126, 119-124. https://doi.org/10.1115/1.1725170

[3] Taber, J.J., Martin, F.D. and Seright, R.S. (1997) EOR Screening Criteria Revisited Part 1: Introduction to Screening Criteria and Enhanced Recovery Field Projects. SPE Reservoir Engineering, 12, 189-198. https://doi.org/10.2118/35385-PA

[4] Shokoya, O.S., Mehta, S.A., Moore, R.G. and Maini, B.B. (2005) Effect of Oil and Flue-Gas Compositions on Oil Recovery in the Flue-Gas / Light-Oil Injection Process. SPE Annual Technical Conference and Exhibition, Dallas, 9-12 October 2005, SPE-97262-MS. https://doi.org/10.2118/97262-MS

[5] Benham, A.L., Dowden, W.E. and Kunzman, W.J. (1960) Miscible Fluid Displacement-Prediction of Miscibility. Transactions of the AIME, 219, 229-237.

https://doi.org/10.2118/1484-G

[6] Kuo, S.S. (1985) Prediction of Miscibility for the Enriched-Gas Drive Process. SPE Annual Technical Conference and Exhibition, Las Vegas, 22-25 September 1985, SPE-14152-MS. https://doi.org/10.2118/14152-MS

[7] Zick, A.A. (1986) A Combined Condensing/Vaporizing Mechanism in the Displacement of Oil by Enriched Gases. SPE Annual Technical Conference and Exhibition, New Orleans, 5-8 October 1986, SPE-15493-MS. https://doi.org/10.2118/15493-MS

[8] Wang, Y. and Orr, F.M. (1998) Calculation of Minimum Miscibility Pressure. The SPE Annual Technical Conference and Exhibition, Tulsa, 19-22 April 1998, Paper SPE 39683. https://doi.org/10.2118/39683-MS

[9] Johns, R.T. and Orr, F.M. (1995) Miscible GAS Displacement of Multi-Component Oils. The SPE Annual Technical Conference and Exhibition, Dallas, 22-25 October 1995, Paper SPE 30798. 
[10] Glasø, O. (1985) Generalized Minimum Miscibility Pressure Correlation (Includes Associated Papers 15845 and 16287). Society of Petroleum Engineers Journal, 25, 927-934. https://doi.org/10.2118/12893-PA

[11] Firoozabadi, A. and Khalid, A. (1986) Analysis and Correlation of Nitrogen and Lean-Gas Miscibility Pressure (Includes Associated Paper 16463). SPE Reservoir Engineering, 1, 575-582. https://doi.org/10.2118/13669-PA

[12] Zhang, H., Hou, D. and Li, K. (2015) An Improved $\mathrm{CO}_{2}$-Crude Oil Minimum Miscibility Pressure Correlation. Journal of Chemistry, 2015, Article ID: 175940. https://doi.org/10.1155/2015/175940

[13] Alomair, O.A. and Garrouch, A.A. (2016) A General Regression Neural Network Model Offers Reliable Prediction of $\mathrm{CO}_{2}$ Minimum Miscibility Pressure. Journal of Petroleum Exploration and Production Technology, 6, 351-365. https://doi.org/10.1007/s13202-015-0196-4

[14] Ge, D., Cheng, H., Cai, M., Zhang, Y. and Dong, P. (2021) A New Predictive Method for $\mathrm{CO}_{2}$-Oil Minimum Miscibility Pressure. Geofluids, 2021, Article ID: 8868592. https://doi.org/10.1155/2021/8868592

[15] Bougre, E.S. and Gamadi, T.D. (2021) Enhanced Oil Recovery Application in Low Permeability Formations by the Injections of $\mathrm{CO}_{2}, \mathrm{~N}_{2}$ and $\mathrm{CO}_{2} / \mathrm{N}_{2}$ Mixture Gases. Journal of Petroleum Exploration and Production, 11, 1963-1971.

[16] Schlumberger (2006) Eclipse User Technical and Reference Manual.

[17] Karaei, M., Ahmadi, A., Fallah, H., Kashkooli, S. and Bahmanbeglo, J. (2015) Field Scale Simulation Study of Miscible Water Alternating $\mathrm{CO}_{2}$ Injection Process in Fractured Reservoirs. Geomaterials, 5, 25-33.

https://doi.org/10.4236/gm.2015.51003 